\title{
Educação histórica e sua influência na formação de professores e em documentos curriculares em Portugal ${ }^{1}$
}

\author{
History education and its influence on teachers' formation and \\ curriculum documents in Portugal
}

\section{La educación histórica y su influencia en la formación de profesores y en documentos curriculares en Portugal}

\author{
Solange Maria Nascimento ${ }^{2}$ \\ Rede Pública do Estado do Paraná, Professora \\ https://orcid.org/0000-0001-8701-6141 \\ Maria Auxiliadora Moreira dos Santos Schmidt ${ }^{3}$ \\ Universidade Federal do Paraná, Professora \\ https://orcid.org/0000-0003-4820-5913
}

Resumo: 0 campo de pesquisa denominado Educação Histórica chegou ao Brasil em 2003, a partir de um evento que teve como convidada a professora lsabel Barca, da Universidade do Minho. A temática da formação de professores e a influência que esse campo da ciência tem sobre a produção de currículos e materiais a serem utilizados por professores de História durante suas aulas é discussão frequente entre os grupos de pesquisadores que se formaram em diversas partes do mundo, mas com ênfase em Portugal e no Brasil. A partir da formação acadêmica da professora lsabel Barca e de suas pesquisas relacionadas ao ensino da história nas últimas décadas (BARCA, 2000, 2018), esta entrevista tem como foco trazer para o presente o percurso percorrido pela pesquisadora e quais seus objetivos futuros.

Palavras-chave: Educação histórica. Formação de professores. Documentos curriculares.

Abstract: The research camp denominated Historic Education arrived in Brazil in 2003 from an event that had as an invited guest the teacher Mrs. Isabel Barca, from Minho University. The thematic of teacher formation and the influence that such scientific field have on curriculum production and materials to be used for History teachers during the classes is a recurrent discussion among researcher groups that

Entrevista produzida logo após o encerramento do XIX Congreso Internacional de Educación Histórica Conciencia histórica y pensamento histórico: Debates teóricos e prácticos, realizado em Santiago de Cali, no período de 14 a 16 de agosto de 2019. Mestre e doutoranda em Educação pela Universidade Federal do Paraná.

Pós-doutora em Didática da História pela Universidade Nova de Lisboa-Portugal; Doutora em História pela Universidade Federal do Paraná. 
had graduated around the globe, mostly Portugal and Brazil. From Mrs. Isabel Barca academic education and her researches related to the teaching of history on last decades (BARCA, 2000, 2018), this interview focuses in bringing to the present the path wander by the researcher and which are her future goals.

Keywords: Historic Education. Teacher formation. Curriculum documents.

Resumen: 1 campo de pesquisa denominado Educación Histórica llegó a Brasil en el 2003, a través de un evento que tuvo como invitada la profesora lsabel Barca, de la Universidad Minho. La temática de la formación de profesores y la influencia que este campo tiene sobre la producción de currículos y materiales a ser utilizados por profesores de Historia durante sus clases é una discusión frecuente entre grupos de investigadores que se han formado en diferentes partes del mundo, pero con énfasis en Portugal y Brasil A partir de la formación académica de la profesora lsabel Barca y de sus consultas relacionadas a la enseñanza de la historia en las ultimas décadas (BARCA, 2000, 2018), esta entrevista tiene como enfoque traer para el presente el camino tomado pela investigadora y cuales son sus objetivos futuros.

Palabras clave: Educación Histórica. Formación de professores. Documentos curriculares.

Recebido em 2 de setembro de 2019 Aceito em 29 de novembro de 2019 Publicado em 28 de julho de 2020

\section{SOBRE A ENTREUISTADA}

A professora Maria Isabel Gomes Barca de Oliveira atua como associada com Agregação na Universidade do Minho. Possui Doutorado em Ensino de História (History in Education) pela Universidade de Londres, ocasião em que foi orientada pelo professor Peter Lee. É Mestra em Ensino de Ciências Sociais pela Universidade de Boston e licenciada em História pela Universidade do Porto. Desenvolve atividades de docência e investigação no campo da cognição histórica e da educação histórica, com diversos projetos e estudos nesse âmbito. Constitui-se como referência essencial sobre os debates no campo da Educação Histórica com uma extensa lista de artigos e obras publicadas.

Pesquisadora: Vamos conversar um pouco sobre sua vida profissional e a Educação Histórica. Em junho de 2014 a senhora, professora lsabel Barca, esteve por algum tempo em Curitiba, como professora visitante, e participou de orientações coletivas de trabalhos de mestrado e doutorado do Programa de Pós-graduação em Educação da Universidade Federal do Paraná, principalmente os ligados ao Laboratório de Pesquisa em Educação Histórica (Lapeduh), coordenado pela Professora Maria Auxiliadora Schmidt. Em 
uma dessas ocasiões, a senhora apresentou-nos uma reflexão sobre o contexto histórico de Portugal na década de 1970 e as discussões sobre ensino de História naquele momento. Em que medida o contexto político e as mudanças que ocorreram em meados da década de 1970 influenciaram os debates educacionais? Que autores influenciaram e foram debatidos naquele momento?

Isabel Barca: Sim, com certeza a revolução democrática em Portugal ocorreu em 1974, concretamente a partir de 25 de abril, quando as Forças Armadas, com um movimento organizado clandestinamente, porque queriam a continuidade da Guerra Colonial, fizeram um golpe de estado, e a partir daí a população aderiu em massa a essa ideia de terminar com a ditadura e procurar terminar com a Guerra Colonial. Pois todos os nossos homens, jovens homens - irmãos, namorados, filhos -, todos eles tinham que ir para a tropa e nomeadamente para a guerra em Angola, Moçambique e Guiné. Portanto, a partir do estado de golpe militar houve uma revolução na qual o povo se envolveu e todas as estruturas sofreram uma grande alteração, na nossa perspectiva uma alteração para melhor.

As escolas, naturalmente, também tiveram essas alterações. Expulsaram muitos dos professores que eram considerados muito afetos ao regime e havia uma palavra para essa situação, o que não era só para as escolas, que era o saneamento, muitas pessoas em várias estruturas foram saneadas, houve também muitas greves. Em relação à história, naturalmente que estava também no cerne de revoluções necessárias no seu ensino e aprendizagem e, portanto, falamos da história no ensino não superior. Houve mudança de direção, os antigos reitores e diretores foram saneados, e foram eleitas missões democráticas para dirigirem as escolas e os liceus, sejam elas primárias, secundárias ou escolas técnicas. No plano da história aboliram-se os manuais que eram altamente censurados e, portanto, os professores tiveram que ensinar, mas sem os manuais e, naturalmente, os que tinham alguma formação política, nomeadamente, eu, tive possibilidades de mais abertamente explanar as minhas ideias em relação à história. E que era uma história, nesta altura, que nós queríamos já que fosse inclusiva, no sentido de olharmos para aqueles que até ali eram os nossos soldados que combatiam, ou seja, o povo moçambicano, angolano, guineense, cabo-verdiano, etc. (em Cabo Verde não houve guerra), mas perante essa situação nós queríamos ver o outro lado. Eu lembro que houve um livrinho de literatura que era para crianças, e que realmente foi muito importante para mim nessa formação de uma perspectiva mais alargada para lá da nossa, que é o 0 outro lado da rua. Uma menina vivia num lado da rua com casas bonitas, todo o conforto, mas e outro lado da rua como era? E um dia ela quis ir ao outro lado conhecer; que era de fato muito diferente daquele conforto todo em que ela vivia. E, portanto, isso pode ser uma analogia que, a nível pessoal, me levou a crer, perceber os manuais dos movimentos de libertação desses países africanos com os quais o exército português ainda estava em guerra, embora soubéssemos que quando eles tomaram conhecimento da revolução houve um movimento de reencontro dos exércitos inimigos, abraçaram-se 
e recusavam-se a combater, muito interessante. Mas voltando à história. Professores que tinham alguma formação política tiveram a possibilidade de ensinar a história de outra forma, e não estou aqui a falar ainda de Educação Histórica, desses princípios em que nós nos movimentamos, mas são princípios que apontam para essa vontade de incluir os alunos, por exemplo, eu propunha-lhes trabalhos de grupo e um pouco mais tarde trabalhos com fontes diversas. Já nesse momento havia uma tentativa de mudança da parte daqueles que tinham alguma consciência de avançar num ensino de história diferenciado em nível de múltipla perspectiva como nós agora trabalhamos.

Pesquisadora: Mas naquele momento ainda não havia a ideia da multiperspectividade; era só uma tentativa?

I. B.: Não. Não havia essa consciência, era uma forma de conhecer o outro, o outro lado, era só uma tentativa. Eu já praticava timidamente, porque havia a polícia política, essa ideia de dar, por exemplo, dois conceitos a mesma situação no que diz respeito ao que se passava em África, isso estava dentro do programa, mas numa perspectiva nacionalista os outros eram maus e os portugueses eram bons. Por exemplo, quando se falava de aldeamentos que eram organizados pelo exército para as populações africanas viverem bem, eu sabia já que o outro lado chamava esses aldeamentos de campos de concentração, e eu lembro que timidamente lá ia dizendo assim, dando algumas dicas, mas sempre de uma maneira muito, muito contida, por causa da polícia política. Então, em nível de múltiplas perspectivas não seriam as múltiplas perspectivas, mas pelo menos o outro lado da história foi sendo cultivado obviamente pela oposição.

Em seguida, no plano das fontes, porque já não tínhamos manuais, foram todos abolidos na disciplina de História; o Ministério da Educação já todo reformulado, com a participação de pessoas que aderiram à revolução, começou a produzir um conjunto de textos e documentos, e estes eram distribuídos para as escolas para os professores, a partir desses materiais, poderem avançar com o trabalho minimamente consistente. № entanto, houve aqui um aspecto que até pode ser contraditório em relação à vossa história da educação no Brasil e do ensino de História que é alguns espaços que pertenciam à História foram substituídos pelos Estudos Sociais e pelas Ciências Sociais, alegando que era preciso conhecer a realidade que estava escondida e que era preciso investigar, era preciso conhecer, era preciso debater nas escolas e, por isso, a História foi reduzida e substituída no $5^{\circ}$ ano de escolaridade, penso que também no $8^{\circ}$, pela disciplina de Estudos Sociais, e essa disciplina tornava-se muito suspeita para aqueles que eram mais de direita, pois era demasiado revolucionário substituir a História por Ciências Sociais; algum tempo depois tudo isso foi abolido, talvez em 1978. Essa substituição da História não terminou logo de vez, mas foi sendo reduzida e reposta progressivamente a disciplina de História. Embarcávamos muito 
nessa ideia de que era preciso conhecer o presente que até ali era proibido conhecer, e naquele contexto justificava-se, fundamentalmente as grandes mudanças à História foram estas: tentar reavivar a história noutras perspectivas, conhecer outros lados, mas, por outro lado, também procurar conhecer o presente que até aquele momento estava escondido. Eram essas as duas vertentes que mais se avultaram nos primeiros anos da revolução e, portanto, entre 1974 e 1978 foi esse o panorama.

Depois, mais tarde, talvez ainda nos anos 1970, foi promulgada uma instrução ministerial; os tempos já eram outros, havia um período já pós-revolucionário, e essa instrução ministerial com objetivo de criar novos manuais, e esses estavam todos na linha da Escola dos Analles, na linha estruturalista, portanto era algo que os professores não entendiam. De uma forma muito abstrata, as grandes estruturas, as grandes conjunturas. Também chamaram-se a esses grandes complexos - complexos histórico-ageográficos -, e isso provocou uma perturbação no ensino da História e na aprendizagem da História, e atinge o ensino universitário e os alunos universitários, pois, por exemplo, quando acabavam o seu curso chegavam ao estágio e tinham medo de ensinar a parte do feudalismo, porque aquilo era demasiado estrutural e nada fazia sentido, era uma história sem sentido. Porque o estruturalismo tem sentido quando nós já conhecemos as raízes e os contextos mais reais, e, portanto, as abstrações podem ser feitas a partir de uma realidade já conhecida, realidades passadas, quando se parte logo do abstrato efetivamente nem os adultos, jovens estudantes e quiçá alguns professores dominavam tais contextos; e os professores universitários tiveram depois que estudar outras linhas, tudo isso causou uma turbulência e foi cavando certo desligar entre história, ciência abstrata e o ensino-aprendizado, que os próprios professores estavam muito preocupados e incomodados por não dominarem suficientemente essa nova linha que foi lançada. Isso foi essencialmente o que aconteceu com a evolução do ensino de história nos anos 1970, pós-revolução, portanto entre 1974 e próximo aos anos 1980.

Pesquisadora: E quais eram os autores que embasavam a formação do professor nessa época?

I. B.: Bem, eu fiz imediatamente antes do 25 de abril a minha formação, e a maior parte dos professores, ou melhor, os que tinham formação, era ainda muito tradicional e de pouco servia. Eu, por minha conta, frequentei um curso de formação de professores e tomei contato com linhas interessantes, como Freinet e outros pedagogos que incitavam ao trabalho com documentos e a história pelo trabalho, obviamente com documentos, Marc Bloch também. Mas isso também cada um buscava ou não, dependendo de seus interesses nessas situações, portanto eram esses, ○ Marc Bloch, ○ Freinet para a parte pedagógica. Havia naturalmente e interessava-me muito a política, e, portanto, todos os autores que apareciam em Portugal com discussão epistemológica eu comprava e lia. E, nessa altura, havia o embate 
entre o Marxismo e a Escola dos Analles e, portanto, eu ia acompanhando isso tudo porque interessava-me de fato orientar-me a mim própria como professora de história.

Pesquisadora: Em 2014, quando a senhora passou por Curitiba, durante essas mesmas aulas da pós-graduação, fez um comentário sobre a Pedagogia do Oprimido, de Paulo Freire, que teria feito parte de um campo de influências no seu pensamento lá na década de 1970 e posteriormente. Atualmente no Brasil, a produção de Paulo Freire tem sido alvo de muitos questionamentos, por conta das nossas questões políticas. A senhora poderia fazer um comentário sobre esse tema? Houve influência do Paulo Freire no pensamento acadêmico em Portugal?

I. B.: Aqui temos situações relacionadas com essa influência do Paulo Freire em Portugal: uma foi naquela fase de transição, que é a revolução democrática, que nós chamamos revolução democrática, e que houve uma necessidade de alfabetizar as populações. Estudantes universitários e até militares criam campanhas de alfabetização, grupos de alfabetização, que iam àquelas zonas mais rurais, àquelas zonas mais distantes dos centros urbanos, fazer essa alfabetização. E aí, naturalmente, os grupos de esquerda ligados a esses alunos universitários tinham contato com o mundo para lá do que se passava em Portugal e trouxeram essa ideia de, com o Paulo Freire, que propôs aos alfabetizadores aquela forma de chegar às populações trabalhadoras e não alfabetizadas, e uma das imagens que lhes davam com frequência era a questão de ir procurar quais as palavras que eram mais significativas para essas pessoas que trabalhavam no campo e que eram também operários em algumas situações não rurais, por exemplo, a imagem do tijolo, o tijolo para um trabalhador operário da construção civil. 0 tijolo seria uma palavra-chave e significativa e seria por aí que poderiam se aproximar daquelas pessoas que queriam alfabetizar. Portanto, a nível revolucionário, nessa época, o Paulo Freire teve de fato importância nessa primeira campanha de alfabetização. Entretanto, a nível universitário, na filosofia da educação, cultivou-se muito a leitura, a análise e a reflexão sobre os textos de Paulo Freire. Eu não sou da filosofia da educação, tive contato marginal com essa área, sei que esses textos eram estudados pelos jovens universitários, mas até que ponto que era interiorizada a mensagem de Paulo Freire, eu tenho muitas dúvidas. Mas o que é curioso é que o Paulo Freire, como leitura universitária, não tinha uma conotação daquela que nós the demos no tempo da alfabetização. Naturalmente tinha uma mensagem humanista, era essa imagem que passava, mas uma imagem transversal a qualquer ideologia. Isso foi algo que sempre me provocou alguma perplexidade. Mas não estou em condições de avançar mais do que isso porque não explorei. Eu me interrogava desde sempre. Mas como é que uns colegas que eu conheço que são da filosofia da educação cultivam tanto o Paulo Freire? E conhecia alguns alunos que mostravam de fato desenvolver alguns pensamentos do Paulo freire, mas penso que não era uma forma muito interiorizada. 
Pesquisadora: Em sua opinião a leitura foi feita, mas parece que a ideologia ou a filosofia não foram compreendidas?

I. B.: Exatamente, em Portugal, nos cursos de filosofia da educação, Paulo Freire é um autor obrigatório e naturalmente citado pelos universitários, e penso que continuará a ser de alguma forma. Mas parece-me que era uma reapropriação desses textos de forma que talvez não chegasse ao âmago de um humanismo que os textos do Paulo Freire encerram. $\mathrm{E}$ há outro momento, e provavelmente isso tem influência em Portugal, quando Paulo Freire ficou muito conhecido nos EUA. Houve nomeadamente na Universidade de Boston, um professor que era de origem cabo-verdiana, portanto, que sabia português, penso que foi ele o tradutor de Paulo Freire nos EUA. E isso teve um impacto muito grande naqueles grupos de educação progressista dentro de um contexto norte-americano. Teve um impacto muito grande naqueles grandes encontros de educação, o evento American Educational Research Association era o maior encontro, não sei se ainda será, mas era o maior encontro de investigares de educação do mundo. 0 Paulo Freire era muito, muito, muito citado e referenciado e trabalhado por muito dos investigadores que apresentavam seus trabalhos. Ora, houve uma vaga de professores, dos politécnicos e das universidades, que tinham feito mestrado na Universidade de Boston, tal como eu, e, portanto, e conhecemos inclusive esse professor que fez a tradução dos textos e chegou a ser professor daqueles meus colegas que eram os que faziam mestrado em ensino de inglês. $E$ talvez, também, isso tivesse influenciado uma entrada mais em força em meios universitários de educação em Portugal. Através desses colegas que já conheciam o Paulo Freire através (do penso que é Donald Macedo). E que provavelmente, isso é uma hipótese, é apenas uma hipótese, também contribuiram para essa disseminação dos textos. A outra questão é a ideia da educação bancária, era de fato trabalhada, tudo bem educação bancária. Não. E na prática? Quando é que se passava da educação bancária para a outra educação? Passavam e muitas vezes ainda passam para uma ou outra ideia e acaba por não ser muito frutuosa para os alunos que investiguem sozinhos, vão para a casa pesquisar. Hoje em dia vão para casa pesquisar em quê? Na net? E depois trazem os seus trabalhos para sala de aula feitos. Não há ainda aquela monitorização que nós sabemos que é necessária e que no nosso caso tem relação com os princípios da educação histórica.

Pesquisadora: E dessa forma a pesquisa do aluno não tem metodologia, não tem - quê tampouco como fazer, e acaba por produzir cópias, pelo menos acontece em alguns ambientes escolares brasileiros.

I. B.: E mesmo que não faça cópia, não é estimulado pelo professor. 0 professor limita-se, ora vai, vai, pesquisa e traz para a aula. E depois vocês apresentam na aula, em 
grupo ou individualmente, mas não há aquele acompanhamento do professor que deve ser um estimulador. Não é um facilitador. É mais que isso, é um estimulador da aprendizagem. E, portanto, dar pistas e acompanhar de alguma forma os trabalhos que os seus alunos vão fazendo.

\section{Pesquisadora: Professora Isabel, a senhora poderia comentar um pouco mais} sobre a sua formação e o que aconteceu lá em 1970? 0 contexto histórico de Portugal?

I. B.: Bem, há de fato esse primeiro contexto que é um aspecto que eu gostaria de relembrar, é aquela questão das novas formações de professor que se estabeleceram nas escolas. Na escola onde eu estava, havia estágio em história. A orientadora de estágio era uma amiga minha e, portanto, tínhamos assim muitas sintonias. Em termos de forma de ver a educação e não só, de ver o mundo, e, portanto, eu, na qualidade de corresponsável pela disciplina, participava muito das reuniões de estágio e, portanto, trabalhava também com eles. E houve um aspecto muito interessante, há aqui alguns elementos que eu já citei, em termos de inspiradores, um seria o Paulo Freire, outro seria o Freinet, da pedagogia pelo trabalho do Freinet, e outros. Que de certa maneira já nos tinham também dado a pista de que era necessário trabalhar com documentos em história. 0 trabalho para a história tinha que ser com documentos. E para que a educação não fosse bancária tínhamos também que pôr os alunos a trabalhar com o quê? Naturalmente com documentos. E nesse estágio cultivou-se muito essa proposta. De forma que houve também outro aspecto pedagógico, e importante, que era do que víamo-nos aproximar do contexto dos alunos. Era todo um construtivismo e que deu origem de fato, não só em Portugal, a um construtivismo mais sistematizado. Através de investigações sistemáticas no campo da educação. Mas nesse caso concreto e no meu entorno, houve o estágio, e aí foi minha amiga, Irene Serpa, que propôs que fizéssemos um levantamento de documentos históricos primários relacionados com os meios em que os nossos alunos viviam e que a partir desses documentos, das suas próprias terras, das suas próprias aldeias, ou da sua própria cidade que se pudesse então trabalhar a história, em uma história local. Inclusive estávamos em uma fase que não havia ainda uma rigidez de programa, como depois mais tarde acabou por acontecer. Embora seja fictícia, mas as pessoas tomaram tudo, essas ficções por lei e agora torna-se mesmo lei porque é muito difícil. Os documentos não dizem isso, mas é difícil contornar a situação, está na cabeça das pessoas e, portanto, é uma ideia feita na cabeça dos diretores de escola, etc. Deixemos essas questões e vamos adiante. A questão desse trabalho no estágio foi muito, muito, muito importante e para ajudar essa proposta um dos estagiários era padre ou tinha sido padre. Eu não me lembro bem. E, portanto, tinha uma formação grande em latim. Os primeiros documentos relacionados com a vida nas aldeias, nessas zonas rurais, eram documentos em latim. E esse estagiário ficou incumbido de traduzir esses documentos. Portanto, foi logo 
um acervo fantástico para aquela escola, que poderia usufruir de documentos de fontes primárias muito interessantes, porque eram as inquirições. $E$ o que são as inquirições? Eram documentos régios. Foram feitas em dois reinos, em dois reinados, em que o rei encarregou um conjunto de delegados seus para irem a todo o país fazer um levantamento daquilo que eram terras pertencentes ao rei. Porque havia uma possibilidade que era uma realidade, só depois viu-se com esse levantamento que muitas terras foram usurpadas pelos grandes senhores. Estes, então, tinham essas terras e depois também apanhavam as terras do rei, daqui e dali, e não deixavam, inclusive, entrar os que eram encarregados de cobrar os impostos para o rei; havia casos até de morte, matavam-nos pura e simplesmente, queriam tomar conta das terras. E, então, esses delegados fizeram um levantamento dos impostos, isso falando em termos atuais, em que os povos das propriedades régias, que se chamavam reguengos, deveriam pagar ao rei. E isso dava logo uma imagem de uma sobrecarga terrível da população rural e que tinha de dar tantas galinhas, tantos animais assim, tantos animais assados, tanto de vinhos, tantos cereais, tanto uma série de impostos em engendro, e os alunos ficavam maravilhados com tudo aquilo. As portagens que se pagavam se quisessem passar por aquelas terras, tudo isso. Portanto, fez-se um levantamento muito interessante e com esses documentos fizeram-se aulas muito interessantes. $E$ eu procurava com os meus alunos quais eram as terras, as aldeias em que eles moravam e, portanto, usava os documentos das suas próprias terras. Ora, claro! lsso acabava por ser uma aprendizagem significativa. Se assustavam...

Pesquisadora: Tinha muito a ver com a realidade do aluno, da família, da criança, eles se sentiam pertencentes à história.

I. B.: Exatamente! Isto, isto! Portanto, foi também um elemento muito forte. Depois houve a publicação de uma obra, um manual de história em que foram utilizadas essas fontes e que acabou por ter influência no país todo, o manual teve sucesso em nível do quinto e sexto anos de escolaridade. Os autores dessa obra continuam, naturalmente, a ter um prestígio muito grande porque foi de fato um upgrade nos manuais. E hoje em dia todos os manuais têm fontes. Desde aí todos os manuais têm fontes. Esse trabalho já começou com as pedagogias de Freinet e não só, também com algumas outras obras francesas. Nesse sentido, estamos a aprofundar neste momento, 1974, mas que também já mostrava a necessidade. Eu tenho alguns livros comprados nessa altura, com os quais é possível trabalhar com os documentos nas aulas, todos de inspiração francesa. 
Pesquisadora: Bem professora, já há muitos anos a senhora vem se dedicando a esta questão da Educação Histórica e acabou se tornando uma referência internacional no campo, seus trabalhos são muito pesquisados. Eu gostaria que falasse a partir de dois momentos da sua formação para chegar à atualidade como uma pessoa, uma pesquisadora que é referência. A primeira é como ocorreu essa aproximação com o Peter Lee e as discussões da Educação Histórica. A outra questão é referente ao diálogo com teoria da mudança conceitual da Maria Eduarda Vaz Moniz dos Santos. Se você podia também comentar sobre isso e como isso a influenciou. E para fechar esta parte: foi desse modo que a Educação Histórica chegou a Portugale Foi a partir da sua formação e aproximação com o Peter Lee, passando pela mudança conceitual que a Educação Histórica chegou a Portugal? Ou o caminho é outro?

I. B.: Foi mais ou menos isso. Começando até em termos cronológicos pela publicação do livro Mudança conceptual da Eduarda Moniz dos Santos teve impacto de fato esse livro. Embora fosse um livro do ensino das ciências, eu naturalmente aderi a ele, porque era importante também para se compreender essas questões de que se começavam a falar fora de Portugal, que era o Construtivismo, mas inicialmente era na área das ciências que o livro, digamos, era cultivado. Inicialmente foram as ciências que avançaram mais nessa proposta de uma cognição que deu origem a esse princípio do Construtivismo na educação, nos anos 1980. Penso que o livro da Eduarda Muniz dos Santos também foi publicado nos anos 1980 em Portugal e que, provavelmente, terá feito sua formação também no estrangeiro.

Quando começo a trabalhar com o livro da Eduarda Muniz dos Santos nas nossas aulas de História, eu inicialmente fiz o mestrado em Ensino das Ciências Sociais, na Universidade de Boston, e de lá trouxe aquela ideia de uma escola ativa e que deveria colocar os alunos em ligação com os recursos para sua aprendizagem. Isso era muito importante para Portugal porque muitos dos nossos alunos vinham de casa sem livros, eram alunos que vinham de casas que nessa altura ainda não tinham televisão e, portanto, era um mundo de ideias ainda muito restringido ao seu próprio meio local. $E$ eu trabalhei muito quando vim de Boston com a ideia dessa aula como centro de recursos. Bati muito sempre por isso, e isso significava que os nossos alunos pudessem em sala ter acesso imediato a alguns recursos, e eu por vezes consegui uma sala com livros e mapas, trabalhos feitos por alunos. No caso da História, esses recursos eram as fontes para o ensino da História.

Portanto, eu estava nessa fase, em termos educacionais, em termos epistemológicos tive uma formação que me levou a desenvolver bastante as propostas da epistemologia do Marxismo, depois da Escola dos Annales e também as teorias que iam chegando muito timidamente a Portugal, de Foucault, por exemplo, e certa desconstrução que deveria ser necessária para ultrapassar aquilo que Foucault dizia, "uma História feita de e para o Homem normal, branco, ocidental." Portanto, eu estava um pouco nessa linha, que 
considerava que era importante ver o outro lado. Eu trazia muito cedo essa minha ideia de querer ver o outro lado, querer ver outras perspectivas. Entretanto, fui para a Universidade do Minho trabalhar precisamente com o ensino da história, porque anteriormente trabalhei com o ensino das ciências sociais em uma universidade, em Vila Real, e que tinha a formação dos professores desde o ensino básico. Portanto, eu focalizei, por força das circunstâncias, o meu pensamento como formadora e como investigadora na história.

A Universidade do Minho, que tinha já algum prestígio como universidade, com uma escola de educação bastante promissora, tinha uma boa biblioteca, e eu encontrei aí livros, mais precisamente os primeiros livros do Peter Lee, do Alarick Dickinson e mais umas revistas que eles publicaram. Li algumas partes desses livros, fiquei muito interessada. Em Portugal, nessa altura, estava em voga a história ao vivo, o bonito no ensino da História é pôr os meninos para fazer teatrinhos sobre reconstruções históricas. Eu nunca aderi muito a isso, também estavam lá esses livros na biblioteca e ainda estarão, penso eu. E então essa linha, mais ligada à discussão da história e do ensino da história, nessa perspectiva de trabalhar com os alunos e pô-los a pensar, já estava integrada nos meus interesses.

$E$ isso, associado ao fato de eu não querer, embora tivesse sido convidada, fazer o doutoramento tão longe, nos Estados Unidos. Vou pensar: "é uma boa possibilidade, Londres é perto de casa” e, portanto, há aqui dois tipos de interesses. Interesses pessoais, que era de fato muito mais conveniente para mim estar perto de casa, pois demorava tanto de avião ir a Londres quando demorava de comboio indo a Lisboa. Portanto, tudo isso se conjugou. Escrevi para o Departamento History Education, já nem lembro como fiz a pesquisa porque a net nessa altura ainda não era o que é agora, mas lá consegui o endereço, marquei uma entrevista, fui a Londres e fui atendida por Alaric Dickinson, que era o diretor do departamento e quando abriu essa possibilidade de eu poder de fato entrar no doutoramento, e foi assim. Fiz o processo todo de inscrição e fui para Londres, comecei a trabalhar primeiro com Alaric Dickinson numa primeira fase, para precisar o foco da minha tese, e quanto se fixou esse foco, foi a questão da provisoriedade da explicação da História, algo que escandalizou meus colegas de educação em outras áreas, que era uma desconsideração pela ciência considerar que essa ciência era provisória, mas era algo que estava muito em discussão na educação na Inglaterra. Trabalhar com várias perspectivas, era isso que eu queria. Eram esses também meus interesses em termos epistemológicos.

E então, depois de ter já um objeto clarificado, comecei a trabalhar com Peter Lee e sinto-me assim agradecida pela oportunidade. Em termos de História, de investigação em história, ligada à epistemologia da História, penso que, na altura, o Lee, praticamente tudo - que via naquelas bibliotecas, tanto do Instituto de Educação como na Biblioteca Geral de Londres, relacionado com filosofia da História, filosofia analítica da História, indicava-me a leitura. Nesse aspecto e nessa forma de nós pesquisarmos, que é própria a entender o 
pensamento dos sujeitos que estamos a investigar. Agora, a metodologia da investigação... essa aprendi-a com os norte-americanos, na Universidade de Boston. Aquela gramática da investigação; inclusive minha dissertação é em uma perspectiva de estudo quantitativo, houve aquele rigor metodológico que ainda não havia na Educação Histórica no momento em que eu cheguei. Havia um psicólogo, o Dr. John Warley, que nos dava assistência, mas ele percebeu que eu estava já com uma formação avançada porque já trazia isso, e justificavase, pois era isso também que me interessava e que eu fui buscar no mestrado, que é saber investigar, fazer uma amostragem, tratar do objeto e depois do problema, uma amostragem, e decidir se qualitativo ou quantitativo, mas quando eu fiz mestrado estava em voga os estudos quantitativos, e eu precisava entrevistar para perceber melhor porque responderam aquilo que responderam. Portanto, eu de fato queria fazer um estudo qualitativo, porque considerava que era mais produtivo, seria mais profundo, mas o desenho do estudo e assim, naturalmente, foi mudado pelas ferramentas no mestrado.

Pesquisadora: Então foi dessa forma que depois, concluindo o doutoramento, a senhora volta para a Universidade do Minho onde já era professora e continua aprofundando seus conhecimentos e começou a orientar?

I. B.: Bem, eu, enquanto era doutoranda, Londres era tão perto que havia partes em que eu estava novamente em Portugal e houve momentos em que dei aulas enquanto fazia o doutorado, havia um ou outro semestre que era necessário, e isso também era uma maneira de eu aproveitar para colher dados e, portanto, para fazer essa parte que eu poderia fazer em casa, sem necessitar de ir à biblioteca e tudo mais. Portanto, eu, já como doutoranda, ia ensaiando algumas novas formas de trabalhar com meus alunos da licenciatura na Universidade do Minho. A Marília Gago foi minha aluna nesse tempo.

Eu queria regressar a Portugal para implementar essa ideia. Embora Peter Lee estivesse convidando-me para produzir mais e ir a mais congressos na área, na esfera anglo-saxônica, no mundo que fala inglês, mas eu ali queria primeiro trabalhar. E, portanto, foi gradual, mas logo a terminar o doutoramento já estava a ocorrer alguns mestrados nas ciências da Matemática, e o diretor do departamento apresenta-me a proposta de eu organizar o dossiê para criar o mestrado em Ensino de História. Essa altura era Supervisão Pedagógica em Ensino da História, e foi aí então... a Marilia Gago esperou para fazer o seu mestrado, já tinha sido minha aluna na licenciatura, também já se aproximou dessas ideias e foi com o mestrado que de fato houve uma impulsão muito grande. Com isso e com outro aspecto, foi obra do acaso, mas foi, logo a seguir, a terminar o mestrado, fui a fazer uma conferência à associação dos professores de história, e as pessoas gostaram imenso, porque era uma visão totalmente desconhecida para quem tinha - como todos nós tínhamos - uma formação essencialmente vinda da França. E, portanto, foi tudo isso que deu origem, 
foi o mestrado e foram aqueles pontos em que eu pensei "como é que eu vou introduzir isto com pessoas que não fazem ideia dessa viragem de tal mudança conceitual", mas vem a prática, porque é muito bonito falar-se e vê sair muito a falar-se, mas depois na prática, na aula, nós não sabemos o que é que se passa. E há muitos indícios de que, por vezes, essa ideia é pouco entendida, é a tal questão, os alunos lá fora fazer os seus trabalhos. Penso que a oficina é assim vista em alguns pontos do País, em Portugal. Há outras pessoas que não, que têm aquilo muito bem já refletido, pensado, a própria associação dos professores de História abriu a possibilidade de fazer cursos com isso e foram feitos cursos, por exemplo, com Marília Gago e, mais tarde, com a Mariana Lagarto, com a Helena Veríssimo e, dessa forma, se aproximava muitíssimo mais das ideias genuínas, agora cada um tem de reconstruir dentro do possível, dentro do contexto possível que tenha a sua frente, a quem se coloca a trabalhar muito bem, mas há muitas más interpretações, e isso é próprio de qualquer boa ideia, assim como a má ideia por vezes é reapropriada pelo seu melhor.

Pesquisadora: Com relação às discussões específicas em Portugal, poderia oferecer um panorama sobre a maneira como alguns debates da Educação Histórica se tornaram elemento fundamental na formação de professores em Portugal?

I. B.: Desde finais da década de 1990 até esta segunda década do século XXI. Podemos dizer que teve já bastante influência por um lado na política educativa, nos próprios documentos que eram emanados. Eu participei num documento do Ministério da Educação em 2001, já orientando para isso. As competências históricas quais eram? Interpretação de fontes, a compreensão, que tinha três vertentes, temporalidade, espacialidade e contextualização. E uma que seria competência que era a comunicação, que depois foi a pouco e pouco ganhando corpo, a ideia da narrativa, aí dentro da compreensão e da comunicação. Depois do meu mestrado estávamos em um momento de reformular e criar novos documentos, educativos, e, então pediram-me, através da Associação dos Professores de História, um parecer sobre o documento em processo, era ainda só o projeto do documento. Mandeilhes as minhas críticas construtivas. 0 Secretário de Estado, que infelizmente já faleceu, era da Matemática, o ensino da matemática muito avançada. Construtivista e tudo mais. Gostou muito e quis que fosse lá coordenar a parte da História e, portanto, tive uma participação no documento curricular que saiu em 2001 e diz respeito ao ensino da história. Tanto que depois o meu grupo, nosso grupo, disse "a lsabel Barca está aqui", certeza que reconheceu - meu discurso no documento e a partir daí, claro, houve de fato impacto, as pessoas atestavam a fazer algo nas suas aulas, nas suas escolas, de acordo com aquilo que esse documento preconizava. A própria Associação dos Professores de História teve também um papel importante nisso, o Presidente da Associação até fez um dos Congressos precisamente denominado $A$ educação histórica em debate. E foi aí que a expressão Educação Histórica 
começou a entrar de uma maneira mais genérica e depois se expandiu. E é curioso que mais tarde já se fala em Educação Matemática, em Educação em Ciências e houve de fato um impacto em que as Associações de Professores também tiveram o seu papel. E, além do nosso mestrado, estão as jornadas que se começaram a fazer, no início do século XXI e, portanto, foi ganhando, ganhando mais força.

Depois do mestrado vieram as pessoas fazer doutorado. As próprias pessoas da Associação dos Professores de História ficaram também motivadas, e Mariana Lagarto vem a Lisboa a fazer o doutorado ao ponto Norte, ao Extremo Norte do País. Vários do centro do País, e, portanto, tudo isso também impulsionado pela ação da Associação de Professores de História em termos de divulgação e dos seus próprios cursos de fundação em que o nosso grupo participava.

Pesquisadora: Em algum momento a senhora sentiu que estaria sob pressão por um movimento político? Era necessário tomar algum tipo de cuidado nessa fase anos 2000 ?

I. B.: Não, não, porque a minha postura não era de caráter político, mas era de caráter de inovação educacional. Era a inovação educacional que estava em jogo.

\section{Pesquisadora: $\mathrm{E}$ isso era respeitado pelo poder público?}

I. B.: Foi respeitado. Aliás, o poder público nessa altura ainda não se pronunciava muito nessas questões. $E$ aqueles que eram mais ativos eram naturalmente pessoas progressistas de vários quadrantes, alguns nem eram, em termos políticos, nem eram de esquerda, mas eram pessoas ativas e progressistas em termos educacionais, sociaisdemocratas, e, portanto, não houve pressões nesse caso.

Pesquisadora: No Brasil existe um movimento preocupante, que é o seguinte: nós temos uma prova chamada ENEM, que é uma prova feita no terceiro ano do ensino médio. E algumas instituições de ensino superior já usam como o nosso vestibular. 0 ENEM normalmente mede possibilidades e profundidade de leitura dos alunos. Em todas as ciências. Então tem prova de todas as disciplinas, no Brasil, no caso do Ensino Médio, são 12 disciplinas. E essa prova externa à escola é feita pelo Ministério da Educação e enviada paras escolas, também não existe uma preocupação com uma prova para o Sul do País, uma prova para - Norte, é a mesma prova para todo mundo. 0 que acontece nos documentos oficiais é que muito do que é pensado para essa prova acaba influenciando o currículo. Em Portugal, por exemplo, o PISA, que é internacional, acaba tendo alguma influência no currículo? 
I. B.: Sim, o PISA tem influência no currículo, mas no currículo das ciências da matemática. Não sei se das línguas estarão muito preocupados com essas questões. Penso que mais na matemática. Mas essa questão não passa pela história, porque a história não tem. Não está dentro do projeto PISA.

Mas em relação aos exames nós conseguimos de fato influenciar. Claro que não foi logo, de imediato. Mas progressivamente, e com todo o trabalho que fizemos, em ligação com a Associação dos Professores de História, porque era uma forma de disseminar pelo País, efetivamente, mudanças positivas do exame de história final, do décimo segundo ano, final do secundário, e assim passa pela inclusão de fontes para serem problematizadas e usadas pelos examinandos nas suas provas. Portanto, houve primeiro essa influência na política educativa na produção de documentos que se repetiu na produção de novos documentos que foram publicados em 2010; foi o nosso grupo, da Educação Histórica, que os produziu, portanto, era coordenado por mim lá na Universidade do Minho. E, portanto, essa política educativa estava sendo influenciada em termos de História de ensino de história e no currículo para as escolas. Os próprios manuais também receberam influências, mais ou menos, mas receberam influências desse cuidado com fontes e certo cuidado com as perguntas às fontes, inclusive com a inclusão de algumas fontes contraditórias, que conseguissem problematizar. Claro que isso é sempre muito complicado, é preciso uma formação muito avançada dos professores para não caírem no relativismo e no tudo vale. Mas houve um trabalho interessante a esse nível. Depois, em 2013, com uma política educativa muito adversa a tudo isso, e que se voltou novamente àqueles objetivos, inclusive mal feitos, e a preocupações só de regurgitação de conteúdo, e não estou a falar só de História. Os próprios exames, os textos de exames mudaram. E isso foi o que eu apresentei no Congresso aqui em Cáli; em nome de dois jovens investigadores que fizeram precisamente esse trabalho de analisar o tipo de perguntas que se faziam nas provas de exame. Entre 2006 e 2018. E de fato a partir de 2013/2014 as provas quase anularam essa pergunta às fontes. Essa proposta de integrar o que as fontes dizem numa resposta narrativa, e passaram a perguntas diretas e respostas diretas. Nós temos esperanças que se mantiver essas novas tendências de política educativa, que os exames sejam novamente considerados. Porque foi uma pena, os professores estavam já preocupadíssimos com a utilização de fontes e era um primeiro passo para se avançar para perguntas mais complexas. No início não poderia, num exame, aparecer perguntas muito complexas, porque eles não estavam preparados durante o ano para tanto. Mas o fato de eles terem que ir buscar elementos, à fonte, para os integrar nas suas próprias narrativas já era um avanço em Portugal. 


\section{Pesquisadora: A senhora refletiu sobre a formação do professor, que talvez até o} professor não estivesse preparado para um trabalho com as fontes. Eu sei que a Convenção de Bologna produziu uma modificação significativa no currículo de formação de professores. E já há muitos professores formados pela Convenção de Bologna. Essa modificação melhorou a qualidade da formação docente?

I. B.: Algo mudou. Há uma reestruturação em termos do desenho curricular da formação do professor que, naturalmente, depois vai mexer também com a formação que os professores recebem. Mas é, por exemplo, no plano da História, houve aqui uma turbulência que não foi nada positiva. Porque decidiram, e decidiram de cima e muito rapidamente, que haveria um mestrado no Ensino de História e da Geografia. Integrados. Ora, isso causou, de fato, problemas grandes, porque não havia tradição nenhuma de trabalho entre a História e Geografia a nível universitário. No nosso caso, foi até interessante, engraçado, caricato, por vezes, nós tínhamos o departamento da História no Minho, em Braga, e o departamento de Geografia também da Universidade do Minho em Guimarães na outra cidade. Então praticamente não nos encontrávamos de modo algum. E, por outro lado, havia um dossiê para fazer novos mestrados rapidamente, porque quem não entrasse com os dossiês burocráticos não podia abrir mestrados. E isso para nós era terrivel, porque nós estávamos à frente nas ideias da formação dos professores de história. E depois íamos ficar para trás.

Ora, vejam o meu dilema, eu era coordenadora. E os nossos alunos, o que faziam nossos alunos? lam todos para outras universidades, acabar os cursos? De forma que eu e a Maria Augusta Lima Freitas, historiadora, resolvemos: "vamos abrir um mestrado, nós temos de abrir um mestrado. Não concordamos com a junção de História e Geografia, mas nós não vamos ficar para trás." E então entramos em contato com a geografia, e as coisas correram muito bem. Claro que inicialmente nem sequer nos conhecíamos, o meu colega da geografia dava aulas em Guimarães e morava em Coimbra, em outra cidade ainda mais longe. Por acaso eu andava com contatos de trabalho com o mestrado de Coimbra e eu disse "por acaso eu vou à Universidade de Coimbra em tal dia." "Ah, então, encontramos em Coimbra." "E então como é que nos encontramos?" "eu estou com o carro tal", "eu vou de comboio", "eu vou de trem", e ele ia esperar numa estação num carro, assim e assim, portanto já poderia identificálo, e vou com uma pasta assim e assim. Portanto fizemos esse casamento entre história e a geografia, que correu muito bem. Trabalhamos desde o primeiro dia num café e depois de outras formas, na universidade, às vezes de um lado, às vezes do outro. Nós avançamos rapidamente. Mas isso naturalmente causou muita turbulência, porque nós recebemos depois os alunos de geografia e de história para trabalhar no âmbito de ensino de história e de geografia. E os alunos de geografia eram bons alunos, que queriam ter um lugar seguro como professores e, portanto, foram os melhores que entraram, e os nossos de história também queriam aprender, e os de geografia queriam aprender, mas inicialmente faziam perguntas totalmente sem nexo. "Ó, professora, o quê que foi primeiro: o Renascimento ou a ldade Média?". 
Tinha de fato um ensino individualizado, porque realidades muito diferentes entre geografia, os de geografia e os de história, isso para história. Para a geografia, éramos nós, os de história, que não sabíamos muito. Não é? E havia poucos professores para trabalhar essas questões. De forma que inicialmente foi complicado, e, então, os colegas da geografia também não estavam satisfeitos com isso, e nós desenvolvemos um movimento de contestação. Em algum momento, talvez nas Jornadas de 2011 ou 2012, desenvolvemos uma petição nacional para ser discutido no parlamento. Isso foi até o fim, depois foi até um colega de geografia que avançou, porque estava fora em sabática e conseguiu separar novamente a história e a geografia.

Então nós temos o ensino mestrado profissionalizante, penso que é próximo do ProfHistória vosso. Mas que é em Portugal, pelo menos na Universidade do Minho e também na Universidade de Porto, assume já características de Educação Histórica. Não é, assim, em todo o lado, mas no Norte, nas duas universidades do Norte há essa preocupação. Aqui o relatório que os alunos têm de fazer no final é uma minidissertação do mestrado, de investigação. Portanto, há alguns problemas. 0 impacto que isso tem nas aulas ainda não está medido, ainda não está estudado, não é isso, a ideia ainda é nascente, mas, no final, esses alunos de geografia, pelo menos aquelas primeiras vagas, aplicaram-se muito, e conseguiram também fazer suas dissertações que são relatórios, mas na prática acabam por ser dissertações também muito valiosas para nós.

Pesquisadora: Professora lsabel, fizemos um percurso imenso aqui. Da década de 1970 aos 2019. E nesse percurso percebe-se que trabalhou com muitas coisas, níveis de ensino diferente. Já pesquisou com crianças pequenas, com o médio, o estágio supervisionado, enfim, já passou por vários níveis de ensino. Qual é a sua pesquisa, ou suas últimas pesquisas agora em 2019 e para os próximos anos?

I. B.: Este ano estou idealizando novas pesquisas que ainda vou desenvolver em 2020, são de fato as narrativas, porque são um diagnóstico muito importante, penso eu, para medir as ideias. Em termos não só de identidades, mas outras, que os nossos jovens trazem da vida, da sua escolaridade. Em Portugal a disciplina de História é obrigatória até o nono ano, a partir desse momento uns podem ter história, mas a maioria não tem, e, portanto, como é que ficam nossos jovens no final dessa história para todos.

Isso naturalmente não tem a ver com exames de avaliação. Tem a ver com nossa recolha de concessões históricas e de consciência histórica, esse eixo de investigação não quero perder. Mas com essas modificações e todas essas incertezas, que eu chamo incerteza complexa dos nossos dias, há outros aspectos da investigação no campo da Educação Histórica que me parecem pertinentes. E, portanto, como já tenho vindo, de certa maneira, a mostrar, estou preocupada com a questão da explicação. Penso que é muito 
importante os nossos jovens ganharem competências explicativas que não sejam a simples regurgitação das explicações já dadas pelos historiadores. Estou a pensar em desenhar também um projeto nesse campo e já tenho delineado um conjunto de propostas que vou fazer a algumas jovens investigadoras para me acompanharem nesse percurso. Voltar a algo que foi no início também a minha preocupação da explicação provisória em História. Penso que é importante neste momento, para nós nos guiarmos minimamente. Não vamos ter soluções, mas guiarmo-nos minimamente numa projeção dos cenários, e, portanto, trabalharmos para os cenários que nos interessam e tentarmos combater os cenários que nós consideramos perniciosos em relação aos tempos que nós vivemos. A história dá-nos uma série de pistas. Não nos dá lições, mas nos dá uma série de pistas.

Pesquisadora: É verdade. E aí vamos seguindo as direções, que é o que a senhora fará. Muito obrigada, professora. Muito bom. Espero que tenha gostado.

I. B.: Sim, sim. la buscar coisas que eu já não tinha aqui na minha gaveta, assim, mas a frente, está lá atrás. Também eu agradeço.

\section{REFERÊNCIAS}

BARCA, I. 0 pensamento histórico dos jovens: idéias dos adolescentes acerca da provisoriedade da explicação histórica. Braga: Centro de Estudos em Educação e Psicologia, Instituto de Educação e Psicologia, 2000.

BARCA, I. Pensamento histórico e consciência histórica: teoria e prática. In: OLIVEIRA, T. A. D. (org.). Ideias chave para a educação histórica: uma busca de linter)identidades. Curitiba: W.A. Editores, 2018.

Roteiro, Joaçaba, U. 45, p. 1-18, jan./ dez. 2020 | e22709 |E-ISSN 2177-6059 